\section{THU0537 ASSOCIATION BETWEEN BIG FIVE PERSONALITY TRAITS AND RESPONSE TO MULTIDISCIPLINARY PROGRAM IN PATIENTS WITH CHRONIC LOW BACK PAIN: A PROSPECTIVE STUDY}

M.E. Ibrahim ${ }^{1,2}$, K. Weber ${ }^{3}$, S. Genevay ${ }^{1} .{ }^{1}$ Rheumatology, University Hospitals of Geneva, Geneva, Switzerland; ${ }^{2}$ Rheumatology, Suez Canal University, Ismailia, Egypt, ${ }^{3}$ Medical Direction, University Hospitals of Geneva, Geneva, Switzerland

Background: Chronic back pain is a multifactorial condition, which cannot be thoroughly addressed without understanding the psychological factors that influence its onset, maintenance and the response to its management. Patient attitudes and personality traits often determine how they experience pain, how they adjust to it, and their response to the different management strategies.

Objectives: This study aimed to identify whether patients with specific Big Five personality traits are more likely to seek medical care, and to uncover whether there is an association between personality and the patient's response to multidisciplinary functional rehabilitation program.

Methods: 97 patients (57\% male) aged 41.1 (10.1) with chronic low back pain, enrolling in an intensive 4 week multidisciplinary functional rehabilitation program, completed the NEO Personality Inventory-Revised (NEO PI-R) at baseline. Outcome was assessed at treatment admission and discharge, and at 6 months follow up, including Core Outcome Measure Index (COMI), Tampa Scale for Kinesiophobia (TSK), Oswestry Disability Index (ODI) and Hospital Anxiety and Depression Scale (HADS).

Results: Both men and women had significantly lower scores in the Openness to Experience domain and significantly higher scores in the Conscientiousness domain than the average general population. At baseline, Neuroticism was found to correlate positively with TSK and HADS. Low Openness to Experience, and low Extraversion correlated with high HADS at baseline as well. Analysis of the follow up data showed a significant reduction in the COMI, ODI, HADS and TSK at the end of the program, and at 6 months follow up. There was no correlation between the improvement in COMI, ODI or TSK scores after 6 months and any of the 5 domains of the NEO PI-R

Conclusions: Low Openness to Experience and high Conscientiousness seem to be key factors of chronicity in patients with low back pain. Significant decrease in pain, disability as well as depressive and anxious moods showed that these patients were effectively treated by the multidisciplinary functional rehabilitation program regardless of their personality traits.

Disclosure of Interest: None declared

DOI: 10.1136/annrheumdis-2018-eular.4416

\section{THU0538 PATIENTS WITH CHRONIC LOW BACK PAINORIENTED TO FUNCTIONAL RESTORATION PROGRAM ARE YOUNGER, WITH HIGHER SMOKING AND LONGER SICK LEAVE: A CROSS- SECTIONAL STUDY OF 166 PATIENTS}

M. Assadourian ${ }^{1}$, F. Bailly ${ }^{1}$, P. Letellier ${ }^{1}$, S. Ascione ${ }^{1}$, M. Le Ralle ${ }^{1}$, A. Potel ${ }^{1}$, L. Morardet ${ }^{1}$, V. Foltz ${ }^{1}$, A. Dupeyron ${ }^{2}$, N. Ibrahim ${ }^{3}$, I. Griffoul-Espiltalier ${ }^{4}$, B. Duplan ${ }^{5}$, J. Beaudreuil ${ }^{6}$, B. Fautrel ${ }^{1}$, L. Gossec ${ }^{1} .{ }^{1}$ Pitié Salpêtrière Hospital, Paris; ${ }^{2}$ Nîmes Hospital, Nîmes; ${ }^{3}$ La Source Hospital, Orléans; ${ }^{4}$ Tours Hospital, Tours; ${ }^{5}$ Reine Hortense Hospital, Aix les Bains; ${ }^{6}$ Lariboisière Hospital, Paris, France

Background: Functional Restoration Programs (FRP) are multi-disciplinary programs that have demonstrated effectiveness to promote functional status and return to work in patients with chronic low back pain (cLBP $)^{1 ; 2 ; 3}$ and moderate or high disability.

Objectives: To explore the characteristics of CLBP patients oriented or not towards a FRP.

Methods: This was an observational cross-sectional, multi-centric study in France in 2017. Consecutive patients with $\operatorname{cLBP}$ ( $>6$ weeks) with or without radiculalgia, aged 18-66 years and visiting the rheumatologist for CLBP were included. Patient and disease characteristics were collected. Patients oriented or not towards a FRP were compared in particular for demographic characteristics, duration of sick leave over the past 12 months, smoking, ongoing aerobic physical activity (patient-reported as <or at least 30 min sessions twice a week), anxiety or depression (Hospital Anxiety and Depression Scale $\geq 11$ ), disability (Oswestry $>40 \%$ ) and kinesiophobia (Tampa Kinesiophobia Scale $>40$ ).

Results: In all, 166 patients were analysed: median age 48 years, median cLBP duration 5 years, and $100(60 \%)$ were females. Overall, $62(37 \%)$ were proposed for a FRP. Patients oriented towards a FRP, versus not, were more frequently male $(50 \%$ vs $44 \%, p=0.04)$, younger (median 46 vs 52 years, $p=0.02$ ), and had lower pain levels (median 6 vs 7 of $0-10$ numeric scale, $p=0.006$ ). They had longer sick leave (mean 18 vs 10 weeks/year, $p=0.006$ ), were more frequently smokers ( $33 \%$ vs $23 \%, p=0.02$ ), had similar pain duration ( 60 month vs $72, p=0.32$ ), functional disabilities ( $39 \%$ vs $49 \%, p=0.22)$, kinesiophobia ( $62 \%$ vs $55 \%, p=0.65)$, anxiety $(52 \%$ vs $55 \%, p=0.60)$ and depression score $(40 \%$ vs $35 \%, p=0.54)$, but less physical activity practice ( $38 \%$ vs $54 \%, p=0.04$ ).

Conclusions: Patients oriented towards a FRP were younger and more often males, with higher smoking and longer sick leave. It appears that kinesiophobia functional status and duration of low back pain didn't influence the orientation toward a FRP. More comprehensive assessments of patients with CLBP are needed; multifactorial questionnaires such as StartBack or BP2 may be useful to orient patients towards FRPs.

\section{REFERENCES:}

[1] Poulain C, et al. Eur Spine J 2010 Jul;19(7):1153-61.

[2] Véron O, et al. Ann Readapt Med Phys 2008;51(8):642-9.

[3] Roche-Leboucher, et al. Spine 2011 Dec 15;36(26):2235-42.

Disclosure of Interest: None declared

DOI: 10.1136/annrheumdis-2018-eular.3968

\section{THU0539 \\ MECHANICAL TRACTION FOR LUMBAR RADICULAR PAIN: SUPINE OR PRONE? A RANDOMISED CONTROLLED TRIAL}

M. Bilgilisoy Filiz' ${ }^{1}$ Z. Kılıç ${ }^{2}$ A. Uçkun ${ }^{3}$, T. Çakır ${ }^{4}$, S. Koldaş Doğan ${ }^{1}$, N. F. Toraman ${ }^{1} .{ }^{1}$ Physical Medicine and Rehabilitation, Antalya Training and Research Hospital, Antalya, Turkey, Antalya; ${ }^{2}$ Physical Medicine and Rehabilitation, Ankara Atatürk Training and Research Hospital, Antalya, Turkey, Ankara; ${ }^{3}$ Physical Medicine and Rehabilitation, Mut State Hospital, Mersin; ${ }^{4}$ Physical Medicine and Rehabilitation, Private Likya Hospital, Antalya, Turkey

Background: Mechanical lumbar traction has been used to treat spinal disorders and low back pain for centuries, since Hippocrates $\left({ }^{2,3}\right.$ Although the supine position is generally preferred, the patient may also be positioned prone during traction treatment $\left({ }^{4,5}\right.$ However, to the best of our knowledge, no studies have compared the effects of lumbar traction in these two different positions for patients with chronic LBP.

Objectives: To compare the effects of mechanical lumbar traction either in the supine or prone position with conventional physical therapy(PT) in patients with chronic low back pain(LBP) and lumbosacral nerve root involvement in terms of disability, pain, and mobility.

Methods: Participants $(n=125)$ were randomly assingned to receive 15 sessions of PT with additional mechanical lumbar traction either in the supine position (supine traction group), or in the prone position (prone traction group), or only PT without traction(PT only group). Patients were assessed at baseline and at the end of the PT sessions in terms of disability, pain, and mobility. Disability was assessed using the modified Oswesty Disability Index (ODI); pain was assessed using a visual analogue scale (VAS); and lumbar mobility was assessed using the modified lumbar Schober test ( $\mathrm{mLST}$ ).

Results: 118 patients completed the trial. All groups improved significantly in the ODI, VAS, and $\mathrm{mLST}(\mathrm{p}<0.05)$ (table 1). In the between-group analysis, improvements of ODI and VAS were found significantly better in the prone traction group compared with the PT only group (adjusted $\mathrm{p}=0.031$ and.006, respectively).

Conclusions: Addition of traction in prone position to other modalities resulted in larger immediate improvements in terms of pain and disability, and the results suggest that when using traction, prone traction might be first-choice. Further research is needed to confirm the benefits of lumbar traction in the prone position.

REFERENCES:

[1] Marketos SG, Skiadas P. Hippocrates. The father of spine surgery. Spine 1999;24:1381-7.

Abstract THU0539 - Table

\begin{tabular}{|c|c|c|c|c|c|c|c|c|c|}
\hline & \multirow{2}{*}{\multicolumn{2}{|c|}{$\begin{array}{l}\text { Supine traction group } \\
\qquad(n=39) \\
\text { postintervention }\end{array}$}} & \multirow[b]{2}{*}{$P$} & \multicolumn{3}{|c|}{$\begin{array}{l}\text { Prone traction group } \\
\qquad(\mathrm{n}=39)\end{array}$} & \multicolumn{3}{|c|}{$\begin{array}{l}\text { Only PT group } \\
\qquad(\mathrm{n}=40)\end{array}$} \\
\hline & & & & preintervention & postintervention & $P$ & preintervention & postintervention & $P$ \\
\hline ODI & $50.4 \pm 22.5$ & $33.2 \pm 15.5$ & .001 & $53.8 \pm 15.1$ & $35.9 \pm 15.9$ & .001 & $49.5 \pm 15.1$ & $40.9 \pm 17.6$ & .002 \\
\hline VAS & $8.0 \pm 1.6$ & $4.3 \pm 2.2$ & .001 & $8.0 \pm 1.7$ & $3.7 \pm 2.7$ & .001 & $7.7 \pm 1.5$ & $5.2 \pm 2.3$ & .001 \\
\hline $\mathrm{mLST}$ & $19.4 \pm 1.9$ & $20.7 \pm 1.8$ & .001 & $18.8 \pm 1.8$ & $20.5 \pm 1.3$ & .001 & $19.7 \pm 1.9$ & $20.8 \pm 1.7$ & .001 \\
\hline
\end{tabular}

